\title{
The value of right ventricular longitudinal strain in the evaluation of adult patients with repaired tetralogy of Fallot: a new tool for a contemporary challenge
}

\author{
Luís Almeida-Morais, ${ }^{1}$ Tiago Pereira-da-Silva, ${ }^{1}$ Luísa Branco, ${ }^{1}$ Ana T. Timóteo, ${ }^{1}$ Ana Agapito, ${ }^{1}$ \\ Lídia de Sousa, ${ }^{1}$ José A. Oliveira, ${ }^{1}$ Boban Thomas, ${ }^{2}$ Nuno Jalles-Tavares, ${ }^{2}$ Rui Soares, ${ }^{1}$ Ana Galrinho, ${ }^{1}$ \\ Rui Cruz-Ferreira ${ }^{1}$ \\ ${ }^{1}$ Department of Cardiology, Hospital de Santa Marta, Centro Hospitalar de Lisboa Central; ${ }^{2}$ MRI Caselas, Lisbon, \\ Portugal
}

\begin{abstract}
Objective: The role of right ventricular longitudinal strain for assessing patients with repaired tetralogy of Fallot is not fully understood. In this study, we aimed to evaluate its relation with other structural and functional parameters in these patients. Methods: Patients followed-up in a grown-up CHD unit, assessed by transthoracic echocardiography, cardiac MRI, and treadmill exercise testing, were retrospectively evaluated. Right ventricular size and function and pulmonary regurgitation severity were assessed by echocardiography and MRI. Right ventricular longitudinal strain was evaluated in the four-chamber view using the standard semiautomatic method. Results: In total, 42 patients were included (61\% male, $32 \pm 8$ years). The mean right ventricular longitudinal strain was $-16.2 \pm 3.7 \%$, and the right ventricular ejection fraction, measured by MRI, was $42.9 \pm 7.2 \%$. Longitudinal strain showed linear correlation with tricuspid annular systolic excursion $(\mathrm{r}=-0.40)$ and right ventricular ejection fraction $(\mathrm{r}=-0.45)$ (all $\mathrm{p}<0.05)$, which in turn showed linear correlation with right ventricular fractional area change $(r=0.50)$, pulmonary regurgitation colour length $(r=0.35)$, right ventricular end-systolic volume $(r=-0.60)$, and left ventricular ejection fraction $(r=0.36)$ (all $\mathrm{p}<0.05)$. Longitudinal strain $(\beta=-0.72,95 \%$ confidence interval $-1.41,-0.15)$ and left ventricular ejection fraction $(\beta=0.39,95 \%$ confidence interval $0.11,0.67)$ were independently associated with right ventricular ejection fraction. The best threshold of longitudinal strain for predicting a right ventricular ejection fraction of $<40 \%$ was $-17.0 \%$. Conclusions: Right ventricular longitudinal strain is a powerful method for evaluating patients with tetralogy of Fallot. It correlated with echocardiographic right ventricular function parameters and was independently associated with right ventricular ejection fraction derived by MRI.
\end{abstract}

Keywords: Longitudinal strain; right ventricular function; tetralogy of Fallot; 2D-speckle tracking

Received: 27 November 2015; Accepted: 30 April 2016; First published online: 26 May 2016

$\mathrm{T}$ Etralogy of Fallot is the most COMmon cyanotic CHD, with a survival rate of $\sim 70 \%$, 40 years after surgical repair. ${ }^{1,2}$ Although surgery improves prognosis, it is not a curative procedure, leaves residual lesions, and alters ventricular structure and dynamics. ${ }^{3}$ Postoperative pulmonary regurgitation is common and has an adverse impact on right ventricle

Correspondence to: L. Almeida-Morais, MD, Department of Cardiology, Hospital de Santa Marta, Rua de Santa Marta, no. 50, 1169-024 Lisbon, Portugal. Tel: +351213594000; Fax: +351213144 916; E-mail: lmmorais88@gmail.com haemodynamics, leading to eventual ventricular dilation and systolic dysfunction. ${ }^{4}$ Right ventricular dysfunction confers a dismal long-term prognosis in patients with repaired tetralogy of Fallot, with reduced exercise capacity and increased risk of ventricular arrhythmias and sudden death. ${ }^{5,6}$ Therefore, right ventricular dilatation and systolic dysfunction are criteria for pulmonary valve intervention for significant pulmonary valve regurgitation. ${ }^{7}$

Cardiac MRI is currently the gold standard to assess right ventricular volumes and ejection 
fraction, ${ }^{8}$ useful in selecting the optimal timing for pulmonary valve replacement. ${ }^{9}$ Although it is an invaluable imaging method to assess patients with tetralogy of Fallot who were previously repaired, it is more time consuming than transthoracic echocardiography, impeding its use for repeated evaluations. ${ }^{10}$ In our centre, routine imaging followup is usually performed by echocardiography, and MRI is used when echocardiographic parameters or clinical status suggest that surgical re-intervention is to be considered; however, currently available echocardiographic parameters of right ventricular function have limited accuracy. ${ }^{11}$

Left ventricular global longitudinal strain has been proven to have a good correlation with left ventricular ejection fraction ${ }^{12}$ and to be a better prognostic marker than ejection fraction in a variety of cardiac diseases including chronic heart failure. ${ }^{13}$ Right ventricular longitudinal strain has been hypothesised as an independent predictor of mortality in patients with pulmonary hypertension, with promising results. ${ }^{14}$ Nonetheless, little is known about its role in patients with repaired tetralogy of Fallot.

Therefore, we aimed to assess how right ventricular longitudinal strain correlates with right ventricular function indices, particularly ejection fraction, and functional parameters in patients with repaired tetralogy of Fallot.

\section{Materials and methods}

Patients with repaired tetralogy of Fallot followed-up in the grown-up CHD unit of our centre between 1975 and 2001 were retrospectively analysed. We excluded patients re-operated for pulmonary valve regurgitation and patients with residual right ventricular outflow tract obstruction. Only patients evaluated by 12-lead electrocardiogram, transthoracic echocardiography, MRI, and treadmill exercise testing, within a maximum time span of 12 months, were included.

Baseline clinical characteristics were collected from the medical records, including age, sex, weight, cardiovascular risk factors, medical therapy, surgical procedure, time since surgery, NYHA functional class, and follow-up time.

\section{2-lead electrocardiogram}

From the 12-lead electrocardiogram $(25 \mathrm{~mm} / \mathrm{s}$ for $1 \mathrm{mV}$ ), QRS width and the presence of right bundle brunch block pattern were assessed. Right ventricular strain - overload - pattern was defined as the presence of right bundle brunch block and positive $\mathrm{T}$-waves in leads V1 and V2. ${ }^{15}$

\section{Transthoracic echocardiography}

A complete transthoracic echocardiography was performed in all patients using Vivid-E9 (GE Healthcare Technology, General Electric Vingmed Ultrasound, Horten, Norway) device, with a $3-\mathrm{MHz}$ probe. All examinations were performed by physicians specifically trained and experienced in imaging CHD, and subsequent offline analysis was performed by the same examiner, according to international recommendations. ${ }^{16}$ Standard echocardiographic parameters were calculated; in addition, classic views - parasternal, apical, and subcostal - were adjusted to better assess the right ventricle. Right ventricular diameters were calculated in the parasternal long-axis and four-chamber views. The tricuspid annular systolic, excursion, right ventricular fractional area change, and tricuspid peak systolic velocity of tissue Doppler imaging (tricuspid $S^{\prime}$ ) were assessed in the four-chamber view. The Tei index, or the global performance index, was calculated as the ratio between isovolumetric times - contraction and relaxation - and ejection time, using pulsed Doppler. Pulmonary regurgitation severity assessment included calculation of color Doppler jet length and area, vena contrata, and pressure half-time. Right ventricular longitudinal strain was analysed offline using the acquired cine loops in the four-chamber view with centered right ventricle (EchoPAC Program; GE Healthcare); these were stored with at least three cardiac cycles with a frame rate of 50-80 images/s. Speckle tracking analysis was performed using a validated software for the left ventricle. Endocardial borders were identified by the software and were manually corrected, and myocardial motion was automatically tracked. The right ventricle was divided into six segments: basal, medial, and apical from the septal and lateral walls. Longitudinal strain was determined as the average of all segments (Fig 1). In cases where it was not possible to analyse more than one segment per patient, strain data were not considered.

\section{Cardiac MRI}

All patients were evaluated with cardiac MRI (Signa 1.5-T; GE Healthcare) to assess right and left ventricular volumes and ejection fraction, as well as pulmonary regurgitant volume and fraction.

Right and left ventricular volumes were measured by electrocardiographically triggered, breath-held, cine, steady-state, free-precession imaging sequences, according to the literature. ${ }^{17}$ The right ventricular volumes were obtained using short-axis slices from base to apex covering the entire length of the right and left ventricles; the endocardial contours were manually traced at end systole and end diastole. Assuming there may be a slight delay in end systole 


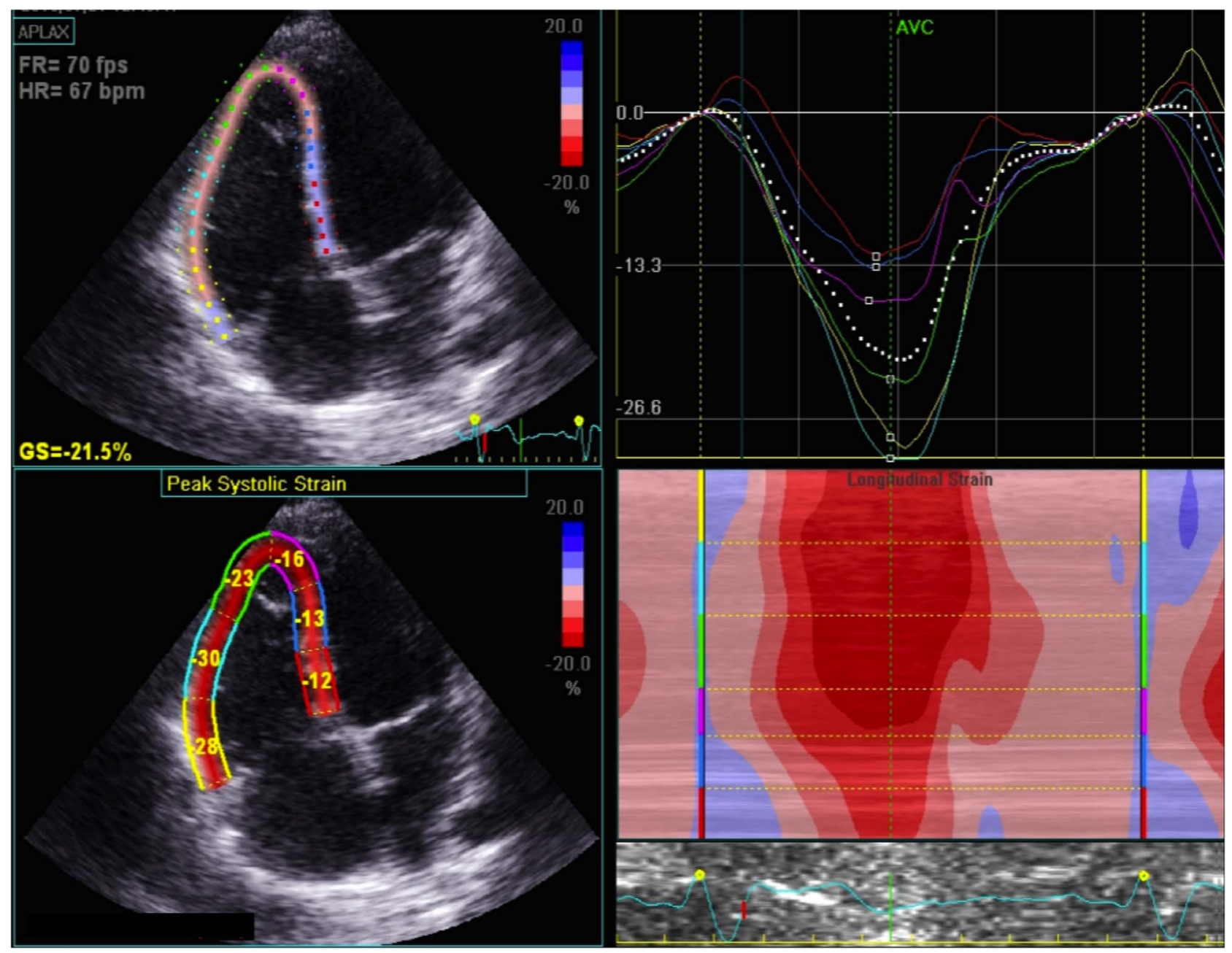

Figure 1.

Right ventricular longitudinal strain assessment by transthoracic echocardiography. Up left: right ventricle-centred, four-chamber view with tracking of the myocardium; down left: strain value for each right ventricular segment; up right: strain curve of the right ventricular segments during the cardiac cycle.

of the right ventricle in comparison with the left ventricle, especially in patients with right bundle branch block, the smallest right ventricular size was used to measure the right ventricular end-systolic volume. The pulmonary regurgitation volume was calculated using phase-velocity sequences, and pulmonary regurgitation was estimated using the ratio of regurgitant flow to total systolic forward flow.

\section{Treadmill exercise test}

Treadmill symptom-limited exercise testing was performed using the Bruce protocol in a Vmax Encore System equipment. In some patients, cardiopulmonary exercise testing with ventilatory expired gas analysis was also performed, using the modified Bruce protocol. In such cases, peak oxygen consumption and minute ventilation-carbon dioxide production relationship were analysed, in addition to the standard parameters. ${ }^{18}$

\section{Statistical analysis}

Baseline demographic and clinical data are described as mean \pm standard deviation for continuous variables and as frequencies and percentages for categorical variables.

Normality (Gaussian distribution) was tested for all continuous variables using the Shapiro-Wilk test. Right ventricular longitudinal strain and right ventricular ejection fraction showed a normal distribution (post-hoc). To assess the association between longitudinal strain and continuous variables, Pearson's or Spearman's correlation was used for normally or non-normally distributed variables, respectively. For categorical variables, comparison of 
longitudinal strain values between groups was assessed using the t-student test or the Mann-Whitney test for normally or non-normally distributed variables, respectively. To evaluate a potential independent association between right ventricular longitudinal strain and ejection fraction, the association between right ventricular function indices and ejection fraction was assessed by univariate - using the same methodology - and multivariate linear regression. Collinearity analysis between parameters was tested earlier. The best cut-off value of right ventricular longitudinal strain for predicting a right ventricular ejection fraction under $40 \%$, which is often considered for surgical repair, ${ }^{19}$ was identified using the receiver operating curve characteristic analysis, as the value with the best combined sensitivity and specificity. The level of significance considered was $\alpha=0.05$. Data were analysed using Statistical Package for the Social Science for Windows, version 20.0 (SPSS Inc, Chicago, Illinois, United States of America).

\section{Results}

\section{Baseline characteristics}

Of the 42 patients included, $61 \%$ were male, with a mean age of $32 \pm 8$ years, and all patients were in NYHA class I or II. The mean time since surgery was $27 \pm 5$ years, and $65 \%$ had a transannular patch in the right ventricular outflow tract (Table 1).

Almost all patients (95\%) showed a right bundle branch block in the 12-lead electrocardiogram (mean QRS width $145 \pm 33 \mathrm{~ms}$ ), and 4 of them (10\%) had this pattern with positive $\mathrm{T}$ waves in leads V1-V2 (Fig 2). Echocardiographic, MRI, and treadmill exercise testing data are detailed in Table 1.

The mean longitudinal strain of the right ventricule was $-16.2 \pm 3.7 \%$. Strain data from at least five of the six segments were obtained in all patients, with a mean of 5.5 segments analysed per patient. The mean right ventricular ejection fraction was $43 \pm 7 \%$, and the left ventricular ejection fraction was $58 \pm 8 \%$, both determined by MRI; the mean pulmonary regurgitation fraction was $45 \pm 18 \%$. Cardiopulmonary exercise testing was performed in $22(53 \%)$ patients.

\section{Association between right ventricular longitudinal strain and other right ventricular function parameters and functional indices}

Repaired tetralogy of Fallot patients presenting an electrocardiogaphic pattern with right bundle branch block and positive T-waves in the V1-V2 leads had significantly lower right ventricular longitudinal strain $(-10.9 \pm 2.8$ versus $-16.4 \pm 2.7 \%, \mathrm{p}=0.025)$.
Among echocardiographic parameters, the longitudinal strain showed significant linear correlation with tricuspid annular systolic excursion $(r=-0.42$, $\mathrm{p}=0.044$ ) and a non-significant trend for association with pulmonary regurgitation severity assessed by colour length $(r=-0.42, p=0.063)$. Longitudinal strain was not associated with other echocardiographic right ventricular function indices such as fractional area change or the Tei index. Longitudinal strain showed a linear correlation with right ventricular ejection fraction assessed by MRI $(r=-0.45, p=0.019) \quad($ Fig 3$)$. There was no significant correlation between right ventricular longitudinal strain and pulmonary regurgitation volume. There was also a trend for association between longitudinal strain and the metabolic equivalents achieved in treadmill exercise testing $(\mathrm{r}-0.45, \mathrm{p}=0.054)$.

\section{Predictors of right ventricular ejection fraction}

In addition to right ventricular longitudinal strain, right ventricular ejection fraction showed a linear correlation with right ventricular fractional area change $(r=0.50, p=0.004)$, colour length of pulmonary regurgitation $(\mathrm{r}=0.35, \mathrm{p}=0.043)$, end-systolic volume $(r=-0.60, p=0.001)$, and left ventricular ejection fraction $(\mathrm{r}=0.36, \mathrm{p}=0.01)$. The presence of a patch in the outflow tract of the right ventricle was associated with a significantly lower right ventricular ejection fraction $(43.8 \pm 7.9$ versus $48.6 \pm 7.4 \%, \mathrm{p}=0.014)$.

By multivariate analysis, longitudinal strain $(\beta=-0.72,95 \%$ confidence interval $-1.41,-0.15$, $\mathrm{p}=0.006$ ) and left ventricular ejection fraction $(\beta=0.39,95 \%$ confidence interval $0.11,0.67$, $\mathrm{p}=0.008$ ) were independently associated with right ventricular ejection fraction. Longitudinal strain had good discriminative power for predicting right ventricular ejection fraction $<40 \%$, with an area under the curve of 0.80 (95\% confidence interval 0.59, 0.99, $\mathrm{p}=0.026$ ) (Fig 4). A longitudinal strain of $-17.0 \%$ was the best cut-off value for identifying a right ventricular ejection fraction $<40 \%$, with $80 \%$ sensitivity and $70 \%$ specificity.

\section{Discussion}

Recently, 2D speckle tracking has emerged as an easy and reproducible tool to assess myocardial deformation. It allows the assessment of left ventricular systolic function, as it is less load dependent than ejection fraction. ${ }^{20}$ Moreover, it has proven to be a strong predictor of cardiovascular events. ${ }^{21,22}$ Analogously, right ventricular speckle tracking analysis has recently been applied to assess right ventricular function in patients 
Table 1. Baseline characteristics.

Baseline characteristics $(n=42)$

Demographic and clinical data

Age (years) (mean $t$ SD)

Male [n (\%)]

Weight $(\mathrm{kg})($ mean $\pm \mathrm{SD})$

NYHA functional class I/II [n (\%)]

Hypertension [n (\%)]

Diabetes mellitus [n (\%)]

Smoker [n (\%)]

Dyslipidaemia [n (\%)]

Arrhythmias [n (\%)]

$\beta$-Blocker [n (\%)]

Anti-arrhythmics [n (\%)]

$32 \pm 8$

$25(61)$

$71 \pm 18$

Anti-thrombotics [n (\%)]

$19(45) / 23(55)$

$9(21)$

$5(12)$

$14(33)$

$4(9)$

$6(14)$

$14(33)$

$5(12)$

$9(21)$

$19(45)$

$27 \pm 5$

Time since surgery (years) (mean $\pm \mathrm{SD}$ )

Right ventricular outflow tract patch [n (\%)]

$27(65)$

Previous palliative surgery $[\mathrm{n}(\%)]$

$18(43)$

Electrocardiographic data

RBBB pattern [n (\%)]

$40(95)$

QRS width (ms)

$145 \pm 33$

Positive T-waves in leads V1-V2 (with RBBB pattern) [n (\%)]

$4(10)$

Transthoracic echocardiography data

Right ventricle dimensions

Four-chamber basal diameter $(\mathrm{mm})($ mean $\pm \mathrm{SD})$

Four-chamber medium-cavity diameter $(\mathrm{mm})($ mean $\pm \mathrm{SD})$

Four-chamber longitudinal diameter $(\mathrm{mm})($ mean $\pm \mathrm{SD})$

Outflow tract diameter (short axis) $(\mathrm{mm})$ (mean $\pm \mathrm{SD}$ )

Four-chamber diastolic area $\left(\mathrm{cm}^{2} / \mathrm{m}^{2}\right)($ mean \pm SD)

Four-chamber systolic area $\left(\mathrm{cm}^{2} / \mathrm{m}^{2}\right)($ mean \pm SD)

Right ventricle function

Tricuspid $\mathrm{S}^{\prime}(\mathrm{cm} / \mathrm{s})($ mean $\pm \mathrm{SD})$

TAPSE $(\mathrm{mm})($ mean $\pm \mathrm{SD})$

Tei index (mean $\pm \mathrm{SD})$

$\mathrm{RV}$ FAC $(\%)($ mean $\pm \mathrm{SD})$

$\mathrm{RV}$ longitudinal strain (\%) (mean $\pm \mathrm{SD}$ )

Pulmonary regurgitation

Jet area $\left(\mathrm{cm}^{2}\right)($ mean $\pm S D)$

Jet length $(\mathrm{mm})($ mean $\pm \mathrm{SD})$

Vena contracta $(\mathrm{mm})($ mean $\pm \mathrm{SD})$

Pressure half-time $(\mathrm{ms})($ mean $\pm \mathrm{SD})$

$49 \pm 10$

$43 \pm 8$

$81 \pm 13$

$27 \pm 6$

$15.2 \pm 5.3$

$8.9 \pm 3.2$

$8.6 \pm 2.7$

$18.9 \pm 5.4$

$0.20 \pm 0.11$

$44 \pm 19$

$-16.2 \pm 3.7$

Cardiac MRI data

$\mathrm{RV}$ end-diastolic volume index $\left(\mathrm{ml} / \mathrm{m}^{2}\right)($ mean $\pm \mathrm{SD})$

$6.8 \pm 2.0$

$41 \pm 8$

$5.2 \pm 1.2$

$120 \pm 51$

$\mathrm{RV}$ end-systolic volume index $\left(\mathrm{ml} / \mathrm{m}^{2}\right)$ (mean $\left.\pm \mathrm{SD}\right)$

$171 \pm 55$

$\operatorname{RVEF}(\%)($ mean $\pm \mathrm{SD})$

LV end-diastolic volume index $\left(\mathrm{ml} / \mathrm{m}^{2}\right)($ mean $\pm \mathrm{SD})$

$98 \pm 39$

$43 \pm 7$

$89 \pm 15$

$40 \pm 15$

$58 \pm 8 \%$

LVEF $(\%)($ mean \pm SD)

$1.9 \pm 0.5$

Ratio end-diastolic RV/LV volume (mean \pm SD)

Pulmonary regurgitant volume $(\mathrm{ml})($ mean $\pm \mathrm{SD})$

$44 \pm 30 \mathrm{ml}$

Pulmonary regurgitant fraction (\%) (mean \pm SD)

$45 \pm 18 \%$

Treadmill exercise test data

METS (mean \pm SD) $(n=42)$

Peak $\mathrm{VO}_{2}(\mathrm{ml} / \mathrm{kg} /$ minute) (mean $\pm \mathrm{SD})(\mathrm{n}=22)$

Predicted peak $\mathrm{VO}_{2}(\%)($ mean $\pm \mathrm{SD})(\mathrm{n}=22)$

Anaerobic threshold (ml $/ \mathrm{kg} /$ minute) $($ mean $\pm \mathrm{SD})(\mathrm{n}=22)$

$\mathrm{VE} / \mathrm{VCO}_{2}$ slope $($ mean $\pm \mathrm{SD})(\mathrm{n}=22)$

$10 \pm 1.8$

$28.7 \pm 6.0 \mathrm{ml} / \mathrm{kg} / \mathrm{minute}$

$75 \pm 12 \%$

$9.9 \pm 2.3 \mathrm{ml} / \mathrm{kg} / \mathrm{minute}$

$27 \pm 5.5$

$\mathrm{FAC}=$ fractional area change $\mathrm{LV}=$ left ventricle $\mathrm{LVEF}=$ left ventricular ejection fraction; METS = metabolic equivalents; NYHA $=$ New York Heart Association; $\mathrm{RBBB}=$ right bundle branch block; $\mathrm{RV}=$ right ventricle; $\mathrm{RVEF}=$ right ventricular ejection fraction; TAPSE $=$ tricuspid annular plane systolic excursion; Tricuspid $\mathrm{S}^{\prime}=$ systolic S-wave amplitude on the tricuspid annulus; $\mathrm{VE} / \mathrm{VCO}_{2}$ slope $=$ minute ventilation-carbon dioxide production relationship slope; $\mathrm{VO}_{2}=$ oxygen consumption 


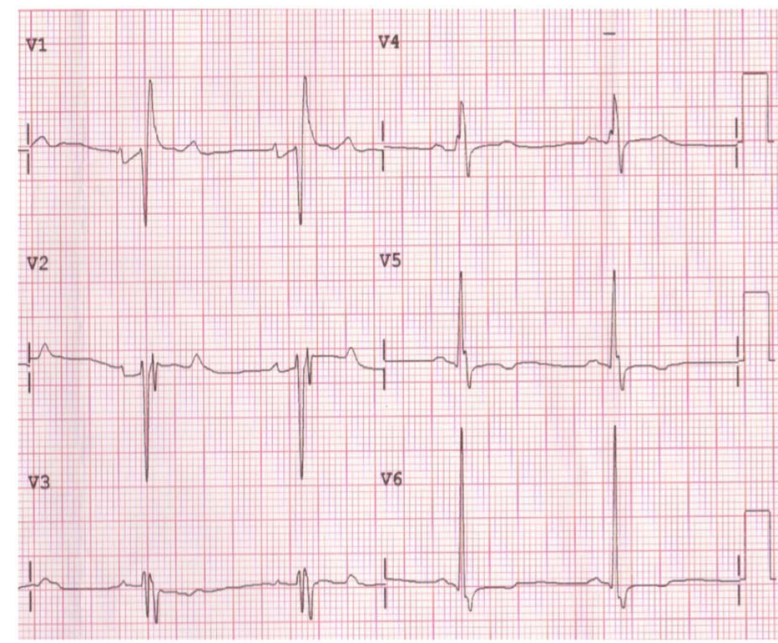

Figure 2 .

Patient's 12-lead electrocardiogram displaying right bundle branch block with positive T-wave in leads V1 and V2.

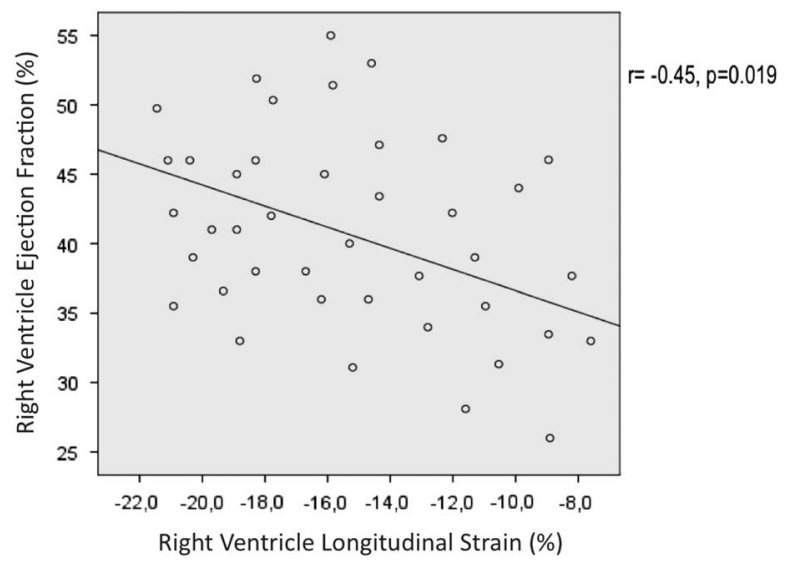

Figure 3.

Correlation between right ventricular ejection fraction measured by cardiac MRI and right ventricular longitudinal strain assessed by speckle tracking analysis.

with pulmonary hypertension, pulmonary embolism, and atrial septal defects. Reasonable correlation between longitudinal strain and right ventricular ejection fraction measured by MRI has been shown as well. $^{23-25}$ Nevertheless, scarce evidence supports the use of $2 \mathrm{D}$ speckle tracking longitudinal strain in repaired tetralogy of Fallot patients.

Right ventricular dysfunction and dilation are the main determinants of long-term outcome in these patients, associated with reduced exercise tolerance, quality of life, and increased risk of arrhythmias, ${ }^{26-28}$ and are critical determinants of surgical intervention for pulmonary valve disease. Nevertheless, the best echocardiographic parameter to assess right ventricular function is currently unknown.

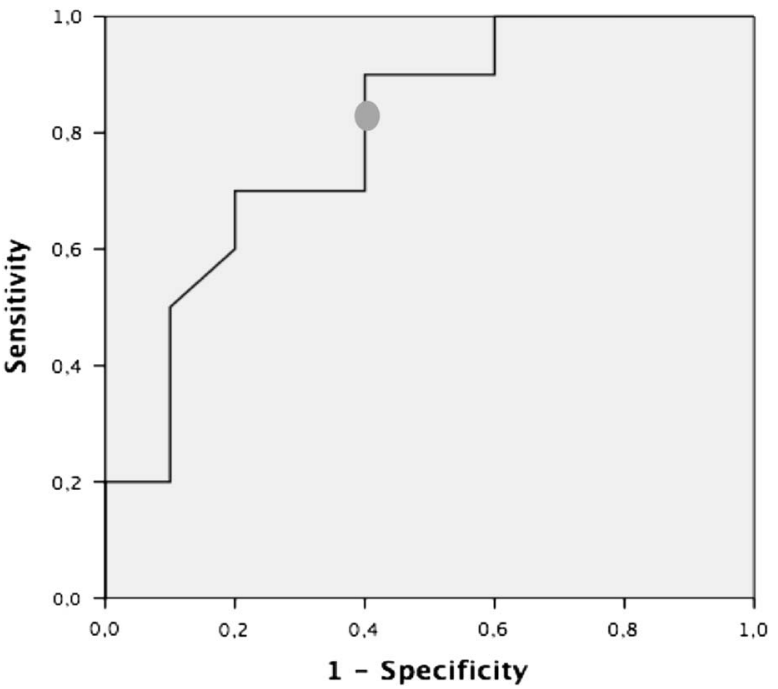

Figure 4.

Receiver operating characteristics curve of the right ventricular longitudinal strain for predicting a right ventricular ejection fraction $<40 \%$. The cut-off value of $-17.0 \%$ had $80 \%$ sensitivity and $70 \%$ specificity (area under the curve 0.80, 95\% confidence interval 0.59, 0.99, $p=0.029$ ).

Right ventricular contractility and stroke volume are mostly determined by longitudinal shortening of deeper muscle fibres inserted in the tricuspid annulus and in the right ventricular apex. Therefore, echocardiographic indices such as tricuspid annular systolic excursion and tricuspid $S^{\prime}$ have been validated against right ventricular ejection fraction measured by MRI and proposed as prognostic relevant parameters. ${ }^{29}$ Koestenberger et al, reported a positive correlation between tricuspid annular systolic excursion and right ventricular ejection fraction in children and adolescents with tetralogy of Fallot after surgical repair. ${ }^{30}$ Nonetheless, these parameters do not account for multisegmentar contractility. Many other parameters have been studied, including fractional area change, which accounts for different segments of the right ventricle, and the global myocardial performance index or the Tei index, but none has emerged as the best parameter to assess right ventricular function. Right ventricular ejection fraction estimation by $3 \mathrm{D}$ echocardiography is being evaluated, but very few data are available in previously operated patients with tetralogy of Fallot, and there is considerable intraobserver and interobserver variability, ${ }^{31}$ mandating more data before routine clinical use.

Longitudinal strain is an easy tool, with low intraobserver and interobserver variability, and it accounts for the majority of segments responsible for right ventricular contraction ejection in a less load-dependent manner than ejection fraction. ${ }^{6}$ 
In these patients with pulmonary regurgitation, the right ventricle is often enlarged and its curvature is no more longitudinal but rather circumferential. Nonetheless, strain assessment is an angle-independent technique. We evaluated the longitudinal strain of six segments of the right ventricle, including the interventricular septum. The assessment of right ventricle free-wall strain alone has been previously suggested; ${ }^{32}$ however, we believe that the interventricular septum should be included in the region of interest as it also contributes to right ventricular ejection and accounts for interventricular interaction, which plays a major role in right and left ventricular dysfunction in repaired tetralogy of Fallot patients, as previously described. ${ }^{33,34}$ The right and left ventricular ejection fractions were correlated in our cohort. As the closure of the ventricular septal defect alters septal dynamics, including strain values of the septum may increase the prognostic value of right ventricular longitudinal strain. A few data are available on right ventricular longitudinal strain in repaired tetralogy of Fallot patients. Li et al, studied different 2D speckle tracking-derived parameters in these patients and reported a significant reduction in longitudinal strain in children and adults after surgery compared with a sex- and age-matched control group. ${ }^{35}$

Our study results revealed a significant association between right ventricular longitudinal strain and right ventricular ejection fraction by MRI. It was the only echocardiographic parameter that correlated with right ventricular ejection fraction in the multivariate analysis. This finding might have resulted from the fact that both parameters are derived from measurements acquired at end systole. ${ }^{16}$ Longitudinal strain had good accuracy for predicting right ventricular dysfunction (area under curve 0.80), and an absolute value of longitudinal strain less than $17.0 \%$ was associated with $80 \%$ sensitivity and $70 \%$ specificity for predicting right ventricular ejection fraction under $40 \%$, reinforcing the appropriateness of this method for routine evaluation of right ventricular function. Furthermore, longitudinal strain also had a trend for association with pulmonary regurgitation severity, which may reflect a higher contractile stress in a state of volume overload. Longitudinal strain also correlated with metabolic equivalents achieved during treadmill exercise testing. Nonetheless, longitudinal strain was not associated with maximal oxygen consumption, a strong marker of functional status, probably because of the small subset of repaired tetralogy of Fallot patients who also performed cardiopulmonary exercise testing. Of note, the right ventricular longitudinal strain was also associated with left ventricular ejection fraction, reinforcing the ventricular interdependence in these patients. Interestingly, patients presenting an electrocardiographic pattern with right bundle branch block and inappropriate $\mathrm{T}$ wave concordance in $\mathrm{V} 1-\mathrm{V} 2$, a marker of ischaemia or right ventricle pressure or volume overload, also had more severe dysfunction assessed by longitudinal strain. ${ }^{15}$

In conclusion, evaluation of right ventricular longitudinal strain should be considered in the routine echocardiographic evaluation of patients with tetralogy of Fallot who were surgically corrected. It would also help assess the best timing for further noninvasive imaging procedures, especially MRI.

\section{Limitations}

The main limitation of the present study was its retrospective nature; however, the same investigator consulted all clinical files, and all the examinations were performed with a maximum interval of 12 months. This sample may present a subgroup of patients with more advanced disease, in which a complete evaluation by echocardiography, treadmill exercise testing, and cardiac MRI was deemed necessary; however, this is exactly the subgroup where clinical decision for re-operation has to be considered and where the additional value of right ventricular longitudinal strain may be of use. Another limitation is the use of software conceived for the assessment of left ventricular myocardial contractility. In the future, dedicated software should be validated for right ventricular assessment.

\section{Acknowledgements}

None.

Authors' Contributions: All authors have contributed to the study design and data acquisition, analysis, and interpretation. The manuscript was reviewed and approved by all authors.

\section{Financial Support}

This research received no specific grant from any funding agency, commercial, or not-for-profit sectors.

\section{Conflicts of Interest}

None.

\section{References}

1. Bertranou EG, Blackstone EH, Hazelrig JB, Turner ME, Kirklin JW. Life expectancy without surgery in tetralogy of Fallot. Am J Cardiol 1978; 42: 458-466.

2. Cuypers JAAE, Menting ME, Konings EEM, et al. Unnatural history of tetralogy of Fallot: prospective follow-up of 40 years after surgical correction. Circulation 2014; 130: 1944-1953. 
3. Pillutla P, Shetty KD, Foster E. Mortality associated with adult congenital heart disease: trends in the US population from 1979 to 2005. Am Heart J 2009; 158: 874-879.

4. Frigiola A, Redington AN, Cullen S, Vogel M. Pulmonary regurgitation is an important determinant of right ventricular contractile dysfunction in patients with surgically repaired tetralogy of Fallot. Circulation 2004; 110 (Suppl 1): II153-II157.

5. Marie PY, Marçon F, Brunotte F, et al. Right ventricular overload and induced sustained ventricular tachycardia in operatively 'repaired' tetralogy of Fallot. Am J Cardiol 1992; 69: 785-789.

6. Friedberg MK, Fernandes FP, Roche SL, et al. Relation of right ventricular mechanics to exercise tolerance in children after tetralogy of Fallot repair. Am Heart J 2013; 165: 551-557.

7. Endorsed by the Association for European Paediatric Cardiology (AEPC), Authors/Task Force Members, Baumgartner H, Bonhoeffer P, et al. ESC Guidelines for the management of grown-up congenital heart disease (new version 2010): the task force on the management of grown-up congenital heart disease of the european society of cardiology (ESC). Eur Heart J 2010; 31: 2915-2957.

8. Kilner PJ, Geva T, Kaemmerer H, Trindade PT, Schwitter J, Webb GD. Recommendations for cardiovascular magnetic resonance in adults with congenital heart disease from the respective working groups of the european society of cardiology. Eur Heart J 2010 Apr; 31: 794-805.

9. Knauth AL, Gauvreau K, Powell AJ, et al. Ventricular size and function assessed by cardiac MRI predict major adverse clinical outcomes late after tetralogy of Fallot repair. Heart 2008; 94: 211-216.

10. Bernard Y, Morel M, Descotes-Genon V, Jehl J, Meneveau N, Schiele F. Value of speckle tracking for the assessment of right ventricular function in patients operated on for tetralogy of Fallot. comparison with magnetic resonance imaging. Echocardiogr Mt Kisco N 2014; 31: 474-482.

11. Rudski LG, Lai WW, Afilalo J, et al. Guidelines for the echocardiographic assessment of the right heart in adults: a report from the American Society of Echocardiography endorsed by the European Association of Echocardiography, a registered branch of the European Society of Cardiology, and the Canadian Society of Echocardiography. J Am Soc Echocardiogr Off Publ Am Soc Echocardiogr 2010; 23: 685-713; quiz 786-788.

12. Benyounes N, Lang S, Soulat-Dufour L, et al. Can global longitudinal strain predict reduced left ventricular ejection fraction in daily echocardiographic practice? Arch Cardiovasc Dis 2015; 108: 50-56.

13. Nahum J, Bensaid A, Dussault C, et al. Impact of longitudinal myocardial deformation on the prognosis of chronic heart failure patients. Circ Cardiovasc Imaging 2010; 3: 249-256.

14. Fine NM, Chen L, Bastiansen PM, et al. Outcome prediction by quantitative right ventricular function assessment in 575 subjects evaluated for pulmonary hypertension. Circ Cardiovasc Imaging 2013; 6: 711-721.

15. Luna AB de. Clinical Electrocardiography: A Textbook, 4th edn. John Wiley \& Sons, Oxford, United Kindgom, 2012, 571 pp.

16. Lang RM, Badano LP, Mor-Avi V, et al. Recommendations for cardiac chamber quantification by echocardiography in adults: an update from the American Society of Echocardiography and the European Association of Cardiovascular Imaging. J Am Soc Echocardiogr 2015 Jan; 28: 1-39.e14.

17. Kawel-Boehm N, Maceira A, Valsangiacomo-Buechel ER, et al. Normal values for cardiovascular magnetic resonance in adults and children. J Cardiovasc Magn Reson Off J Soc Cardiovasc Magn Reson 2015; 17: 29.

18. Guazzi M, Adams V, Conraads V, et al. Clinical recommendations for cardiopulmonary exercise testing data assessment in specific patient populations. Circulation 2012; 126: 2261-2274.

19. Warnes CA, Williams RG, Bashore TM, et al. ACC/AHA 2008 guidelines for the management of adults with congenital heart disease: a report of the American College of Cardiology/ American Heart Association Task Force on Practice Guidelines (Writing Committee to Develop Guidelines on the Management of Adults With Congenital Heart Disease). Developed in Collaboration With the American Society of Echocardiography, Heart Rhythm Society, International Society for Adult Congenital Heart Disease, Society for Cardiovascular Angiography and Interventions, and Society of Thoracic Surgeons. J Am Coll Cardiol 2008; 52: e143-e263.

20. Amundsen BH, Helle-Valle T, Edvardsen T, et al. Noninvasive myocardial strain measurement by speckle tracking echocardiographyvalidation against sonomicrometry and tagged magnetic resonance imaging. J Am Coll Cardiol 2006; 47: 789-793.

21. Cho G-Y, Marwick TH, Kim H-S, Kim M-K, Hong K-S, Oh D-J. Global 2-dimensional strain as a new prognosticator in patients with heart failure. J Am Coll Cardiol 2009; 54: 618-624.

22. Stanton T, Leano R, Marwick TH. Prediction of all-cause mortality from global longitudinal speckle strain: comparison with ejection fraction and wall motion scoring. Circ Cardiovasc Imaging 2009; 2: 356-364.

23. Jategaonkar SR, Scholtz W, Butz T, Bogunovic N, Faber L, Horstkotte D. Two-dimensional strain and strain rate imaging of the right ventricle in adult patients before and after percutaneous closure of atrial septal defects. Eur J Echocardiogr J Work Group Echocardiogr Eur Soc Cardiol 2009; 10: 499-502.

24. Sugiura E, Dohi K, Onishi K, et al. Reversible right ventricular regional non-uniformity quantified by speckle-tracking strain imaging in patients with acute pulmonary thromboembolism. J Am Soc Echocardiogr Off Publ Am Soc Echocardiogr 2009; 22: 1353-1359.

25. Pirat B, McCulloch ML, Zoghbi WA. Evaluation of global and regional right ventricular systolic function in patients with pulmonary hypertension using a novel speckle tracking method. Am J Cardiol 2006; 98: 699-704.

26. Wald RM, Haber I, Wald R, Valente AM, Powell AJ, Geva T. Effects of regional dysfunction and late gadolinium enhancement on global right ventricular function and exercise capacity in patients with repaired tetralogy of Fallot. Circulation 2009; 119: 1370-1377.

27. Meijboom F, Szatmari A, Deckers JW, et al. Cardiac status and health-related quality of life in the long term after surgical repair of tetralogy of Fallot in infancy and childhood. J Thorac Cardiovasc Surg 1995; 110 (Pt 1): 883-891.

28. Gatzoulis MA, Balaji S, Webber SA, et al. Risk factors for arrhythmia and sudden cardiac death late after repair of tetralogy of Fallot: a multicentre study. Lancet 2000; 356: 975-981.

29. Ramos R, Branco L, Agapito A, et al. Usefulness of tissue doppler imaging to predict arrhythmic events in adults with repaired tetralogy of Fallot. Rev Port Cardiol Orgão Of Soc Port Cardiol Port J Cardiol Off J Port Soc Cardiol 2010; 29: $1145-1161$

30. Koestenberger M, Ravekes W, Everett AD, et al. Right ventricular function in infants, children and adolescents: reference values of the tricuspid annular plane systolic excursion (TAPSE) in 640 healthy patients and calculation of $\mathrm{z}$ score values. J Am Soc Echocardiogr Off Publ Am Soc Echocardiogr 2009; 22: 715-719.

31. Khoo NS, Young A, Occleshaw C, Cowan B, Zeng ISL, Gentles TL. Assessments of right ventricular volume and function using three-dimensional echocardiography in older children and adults with congenital heart disease: comparison with cardiac magnetic resonance imaging. J Am Soc Echocardiogr 2009; 22: 1279-1288.

32. Fukuda Y, Tanaka H, Sugiyama D, et al. Utility of right ventricular free wall speckle-tracking strain for evaluation of right ventricular performance in patients with pulmonary hypertension. J Am Soc Echocardiogr Off Publ Am Soc Echocardiogr 2011; 24: $1101-1108$ 
33. Geva T, Sandweiss BM, Gauvreau K, Lock JE, Powell AJ. Factors associated with impaired clinical status in long-term survivors of tetralogy of Fallot repair evaluated by magnetic resonance imaging. J Am Coll Cardiol 2004; 43: 1068-1074.

34. Piazza L, Chessa M, Giamberti A, et al. Timing of pulmonary valve replacement after tetralogy of Fallot repair. Expert Rev Cardiovasc Ther 2012; 10: 917-923.
35. Li Y, Xie M, Wang X, et al. Evaluation of right ventricular global longitudinal function in patients with tetralogy of fallot by two-dimensional ultrasound speckle tracking imaging. J Huazhong Univ Sci Technol Med Sci Hua Zhong Ke Ji Xue Xue Bao Yi Xue Ying Wen Ban Huazhong Keji Daxue Xuebao Yixue Yingdewen Ban 2010; 30: 126-131. 